NASA Techinical Memorandum 105874

\title{
Propulsion System Performance Resulting From an Integrated Flight/Propulsion Control Design
}

Duane Mattern

Sverdrup Technology, Inc.

Lewis Research Center Group

Brook Park, Ohio

and

Sanjay Garg

National Aeronautics and Space Administration

Lewis Rescarch Center

Cleveland, Ohio

Prepared for the

AIAA Guidance, Navigation, and Control Conference

sponsored by the American Institute of Aeronautics and Astronautics

Hilton Head, South Carolina, August 10-12, 1992

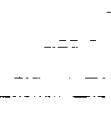




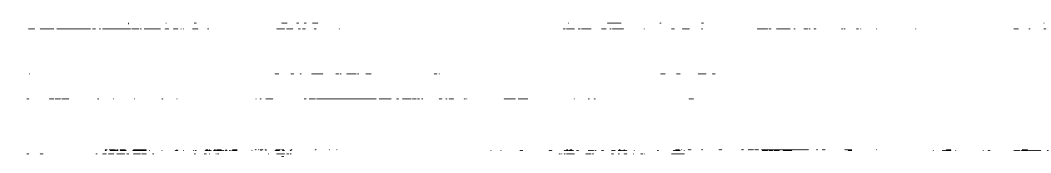




\title{
PROPULSION SYSTEM PERFORMANCE RESULTING FROM AN INTEGRATED
}

\section{FLIGHT/PROPULSION CONTROL DESIGN}

\author{
Duane Mattern \\ Sverdrup Technology, Inc. \\ Lewis Research Center Group \\ Brook Park, Ohío 44142 \\ Sanjay Garg \\ National Aeronautics and Space Administration \\ Lewis Research Center \\ Cleveland, Ohio 44135
}

\section{SUMMARY}

Propulsion-system-specific results are presented from the application of the integrated methodology for propulsion and airframe control (IMPAC) design approach to integrated flight/propulsion control design for a short-takeoff-and-vertical-landing (STOVL) aircraft in transition flight. The IMPAC method is briefly discussed and the propulsion system specifications for the integrated control design are examined. The structure of a linear engine controller that results from partitioning a linear centralized controller is discussed. The details of a nonlinear propulsion control system are presented, including a scheme to protect the engine operational limits: the fan surge margin and the acceleration/deceleration schedule that limits the fuel flow. Also, a simple but effective multivariable integrator windup protection scheme is investigated. Nonlinear closed-loop simulation results are presented for two typical pilot commands for transition flight: acceleration while maintaining flightpath angle and a change in flightpath angle while maintaining airspeed. The simulation nonlinearities include the airframe/engine coupling, the actuator and sensor dynamics and limits, the protection scheme for the engine operational limits, and the integrator windup protection. Satisfactory performance of the total airframe plus engine system for transition flight, as defined by the specifications, was maintained during the limit operation of the closed-loop engine subsystem.

\section{INTRODUCTION}

The concept behind integrated flight and propulsion controls (IFPC) is the management of the interactions between the airframe and the propulsion system to achieve the desired performance of the entire vehicle while reducing the pilot workload. In the past, IFPC had not been necessary because the propulsion system normally generated only a single thrust component and the effects of the airframe on the engine were treated either as disturbances or as performance limits for the aircraft. Recent advances for propulsive systems, such as thrust-vectoring nozzles and the use of multiple nozzles from a single engine core, have increased the flexibility of the control design for aircraft. The Harrier is an example of an aircraft that uses propulsive lift to increase low-speed control effectiveness. Also, vectored thrust is now being used in highly agile aircraft to enhance maneuverability and controllability, for example, for post-stall maneuvers (ref. 1). Vectored thrusts have magnitude and direction and they generate moments because they do not necessarily pass through the aircraft's center of gravity. With propulsive forces and moments being used for more than just forward momentum (pitch control, for example), disturbances to the operation of the engine can influence more than just the forward acceleration of the airframe. Thus, airframe-to-engine coupling, such as (1) inlet distortion due to the angle of attack, the sideslip angle, or hot gas ingestion during hover and (2) bleed flow extraction from the high-pressure compressor for the reaction control system, must be examined more closely during the control design and evaluation. 
The literature on IFPC has generally focused on the mission-level aircraft performance specifications and the resulting closed-loop response of the aircraft. In this report the closed-loop performance of the propulsion subsystem that results from the use of the integrated methodology for propulsion and airframe control (IMPAC) design method is examined for the transition flight mode.

The report is organized as follows: A brief review of the IMPAC design methodology outlines the design steps. The vehicle model is then described, including the details of the propulsion system. Next, the propulsion system operational limits and the engine specifications and how they were accounted for in the centralized control design are discussed. The linear engine controller that resulted from the appliation of the partitioning of the centralized control design is described, and the details of engine control structure are reviewed. The implementation details of the limit protection and the multivariable integrator windup protection are examined. Performance results for the integrated system are shown for two pilot commands typical of the transition flight. Finally, the main results of the paper are summarized.

\section{SYMBOLS}

\section{Airframe}

\begin{tabular}{|c|c|}
\hline $\mathrm{ALR}_{\mathrm{RCS}}$ & left-roll RCS area, in. ${ }^{2}$ \\
\hline $\mathrm{ARR}_{\mathrm{RCS}}$ & right-roll RCS area, in. ${ }^{2}$ \\
\hline $\mathrm{ALY}_{\mathrm{RCS}}$ & left-yaw RCS area, in. ${ }^{2}$ \\
\hline$A R Y_{R C S}$ & right-yaw RCS area, in. ${ }^{2}$ \\
\hline $\mathrm{AP}_{\mathrm{RCS}}$ & pitch RCS area, in. ${ }^{2}$ \\
\hline $\mathrm{h}$ & altitude, ft \\
\hline $\mathrm{p}$ & $\mathrm{roll} \mathrm{rate}, \mathrm{rad} / \mathrm{s}$ \\
\hline q & pitch rate, $\mathrm{deg} / \mathrm{s}$ \\
\hline $\bar{q}$ & dynamic pressure, $1 \mathrm{bm} / \mathrm{ft}^{3}(\mathrm{ft} / \mathrm{s})^{2}$ \\
\hline $\mathrm{RCS}$ & reaction control system \\
\hline r & yaw rate, $\mathrm{deg} / \mathrm{s}$ \\
\hline TLR $\mathrm{RCS}_{\mathrm{R}}$ & left-roll RCS thrust, lbf \\
\hline $\mathrm{TRR}_{\mathrm{RCS}}$ & right-roll RCS thrust, lbf \\
\hline TLY $Y_{R C S}$ & left-yaw RCS thrust, lbf \\
\hline $\mathrm{TRY}_{\mathrm{RCS}}$ & right-yaw RCS thrust, lbf \\
\hline $\mathrm{TP}_{\mathrm{RCS}}$ & pitch RCS thrust, lbf \\
\hline $\mathrm{u}$ & axial velocity, $\mathrm{ft} / \mathrm{s}$ \\
\hline $\mathrm{V}$ & true airspeed, $\mathrm{ft} / \mathrm{s}$ \\
\hline$\dot{\mathrm{V}}$ & acceleration along flightpath, $\mathrm{ft} / \mathrm{s}^{2}$ \\
\hline $\mathrm{v}$ & lateral velocity, $\mathrm{ft} / \mathrm{s}$ \\
\hline
\end{tabular}


$\alpha$

ANG79

$\mathrm{DP} / \mathrm{P}$

ERAM

ETA

FG9

FGE

FGV

N2

N25

N25R

P1

P2

P6

P14 vertical velocity, $\mathrm{ft} / \mathrm{s}$

angle of attack, deg

sideslip angle, deg

rate of change of sideslip angle, $\mathrm{deg} / \mathrm{s}$

left-elevon deflection, deg

right-elevon deflection, deg

rudder deflection, deg

flightpath angle, deg

pitch attitude, deg

roll attitude, deg

heading angle, deg

\section{Engine}

aft-nozzle area, in. ${ }^{2}$

ventral-nozzle area, in. ${ }^{2}$

aft-nozzle vectoring angle, deg

ventral-nozzle vectoring angle, deg

ratio, (P14 - PS14)/P14

inlet ram pressure recovery

ejector butterfly valve angle, deg

aft-nozzle thrust, lbf

total ejector thrust, lbf

ventral-nozzle thrust, lbf

engine fan rotor speed, rpm

engine core rotor speed, rpm

corrected engine core rotor speed, $\mathrm{N} 25 \cdot \sqrt{\left(\mathrm{T}_{\mathrm{std}} / \mathrm{T} 25\right)}$

fan inlet total pressure, psia

recovered inlet pressure, P1.ERAM, psia

tailpipe entrance pressure, psia

fan discharge total pressure in bypass duct, psia 


\begin{tabular}{|c|c|}
\hline$P_{a m b}$ & ambient pressure, psia \\
\hline $\mathrm{PC}$ & combustor \\
\hline PE3 & compressor bleed pressure, psia \\
\hline PS3 & high-pressure-compressor discharge static pressure, psia \\
\hline PS14 & fan discharge static pressure in bypass duct, psia \\
\hline SM2 & fan compressor surge margin \\
\hline $\mathrm{T} 2$ & fan inlet temperature, ${ }^{\circ} \mathrm{R}$ \\
\hline T25 & high-pressure-compressor inlet temperature, ${ }^{\circ} \mathrm{R}$ \\
\hline TE3 & compressor bleed temperature, ${ }^{\circ} \mathrm{R}$ \\
\hline $\operatorname{Tm}$ & metal temperature, ${ }^{\circ} \mathrm{R}$ \\
\hline $\mathrm{T}_{\text {std }}$ & standard temperature, $518.67^{\circ} \mathrm{R}$ \\
\hline W2R & engine inlet mass flow rate, corrected for temperature \\
\hline W25 & engine core mass flow rate, $\mathrm{lbm} / \mathrm{s}$ \\
\hline WB3 & $\mathrm{RCS}$ bleed mass flow rate, $\mathrm{lbm} / \mathrm{s}$ \\
\hline WF36 & fuel flow, lbm/hr \\
\hline$\Lambda$ & propulsion controller integrator windup protection gain matrix \\
\hline$\lambda$ & integrator windup protection scalar gain \\
\hline & General \\
\hline$A_{a}, B_{a}, C_{a}, D_{a}$ & matrices defining linear airframe system \\
\hline$A_{e c}, B_{e c}, C_{e c}, D_{e c}$ & matrices defining linear engine controller \\
\hline $\mathrm{a}$ & subscript, airframe \\
\hline $\mathrm{B}_{\mathrm{ae}}, \mathrm{D}_{\mathrm{ae}}$ & engine-to-airframe interface matrices \\
\hline c & subscript, commanded variables \\
\hline $\mathbf{e}$ & subscript, engine \\
\hline $\mathbf{e}$ & error in tracking command \\
\hline eL & subscript, engine limited variable \\
\hline est & subscript, estimated variable \\
\hline $\mathrm{L}$ & subscript, limited variables \\
\hline $\mathbf{x}$ & subscript, horizontal body-axis thrust component \\
\hline $\mathbf{z}$ & subscript, vertical body-axis thrust component \\
\hline$\overline{\mathrm{u}}$ & perturbed input vector \\
\hline$\overline{\mathbf{x}}$ & perturbed state vector \\
\hline$\overline{\mathrm{y}}$ & perturbed output vector \\
\hline
\end{tabular}




\section{IFPC CONTROL DESIGN METHODOLOGY}

An IFPC design method called IMPAC that takes into account coupling between the airframe and the propulsion system in the early phases of the control design is currently under development at NASA Lewis Research Center. The details of the IMPAC methodology presented in reference 2 will be briefly reviewed. Figure 1 shows the IMPAC methodology flowchart. As seen from the flow chart, there are six major steps in IMPAC: (1) control model generation; (2) centralized or integrated linear control design; (3) controller partitioning into linear subcontrollers; (4) full-envelope subsystem control design;

(5) subsystem nonlinear control design; and (6) full-system evaluation. Steps 1 and 2, the details of the centralized control design, have been presented in references 3 and 4 , and step 3 , controller partitioning, was presented in reference 5. Step 4 considers controller scheduling and operating mode switching logic. Because this paper only considers the control design around a transition operating point, step 4 is not discussed herein. The discussion of steps 5 and 6 , the subsystem nonlinear control design and the integrated system evaluation, will follow after the vehicle model is described.

\section{VEHICLE MODEL}

The model discussed here is used to evaluate the control system around the transition design point while considering many of the airframe and propulsion system nonlinearities. Transition is defined as the flight region in which the forces that support the weight of the aircraft shift from predominately aerodynamic lift to propulsive lift. The model of the airframe, a delta-winged E-7D supersonic short-takeoffand-vertical-landing (STOVL) airframe, is the same linear model that was used in the linear integrated control design discussed in references 3,4 , and 6 . The model of the variable-cycle turbofan engine is a nonlinear component-level model (CLM) (ref. 7). As shown in figure 2 the aircraft is equipped with a convergent-divergent, vectorable aft nozzle; a vectorable ventral nozzle; two wing-root-mounted ejectors; a jet reaction control system (RCS); and the aerodynamic control surfaces: left and right elevons and rudder. At the nominal transition design point the propulsion system supports approximately 60 percent of the weight of the aircraft. The ejector and ventral thrusts were adequately distributed to provide the necessary pitch trim for the aircraft. The RCS was not used for trim, so that the nominal compressor bleed flow was zero. The transition flight-mode model to be discussed is representative of a STOVL aircraft during the approach-to-landing task.

A block diagram of the nonlinear airframe plus engine model that was used for the control evaluation is shown in figure 3. The aircraft portion of the model comprised a linear airframe model, a nonlinear model of the airframe actuators, and a nonlinear RCS model. The small-perturbation linear airframe model was generated at an $80-\mathrm{knot},-3^{\circ}$ flightpath angle, and $7^{\circ}$ pitch attitude flight condition and is of the form

$$
\dot{\bar{x}}_{\mathrm{a}}=\mathbf{A}_{\mathrm{a}} \overline{\mathrm{x}}_{\mathrm{a}}+\mathrm{B}_{\mathrm{a}} \overline{\mathrm{u}}_{\mathrm{a}}+\mathrm{B}_{\mathrm{ae}} \overline{\mathrm{y}}_{\mathrm{ea}} ; \quad \overline{\mathrm{y}}_{\mathrm{a}}=\mathbf{C}_{\mathrm{a}} \overline{\mathrm{x}}_{\mathrm{a}}+\mathrm{D}_{\mathrm{a}} \overline{\mathrm{u}}_{\mathrm{a}}+\mathrm{D}_{\mathrm{ae}} \overline{\mathrm{y}}_{\mathrm{ea}}
$$

where $\bar{u}_{a}, \bar{y}_{a}, \bar{y}_{e a}$, and $\bar{x}_{a}$ are the perturbed airframe input, airframe output, engine-to-airframe interface, and state vectors as shown here: 


$$
\begin{gathered}
\overline{\mathrm{u}}_{\mathrm{a}}=\left[\delta_{\mathrm{e}_{\mathrm{l}}}, \delta_{\mathrm{e}_{\mathrm{r}}}, \delta_{\mathrm{r}}, \mathrm{TLR}_{\mathrm{RCS}}, \mathrm{TRR}_{\mathrm{RCS}}, \mathrm{TLY} \mathrm{RCS}_{\mathrm{RCS}}, \mathrm{TRY}_{\mathrm{RCS}}, \mathrm{TP}_{\mathrm{RCS}}\right]^{\mathrm{T}} \\
\overline{\mathrm{y}}_{\mathrm{a}}=[\mathrm{V}, \dot{\mathrm{v}}, \theta, \mathrm{q}, \gamma, \phi, \mathrm{p}, \beta, \dot{\beta}, \mathrm{r}]^{\mathrm{T}} \\
\overline{\mathrm{y}}_{\mathrm{ea}}=\left[\mathrm{FG} 9_{\mathbf{x}}, \mathrm{FG}_{\mathrm{z}}, \mathrm{FGE}_{\mathbf{x}}, \mathrm{FGE}_{\mathrm{z}}, \mathrm{FGV}, \mathrm{FGV}_{\mathrm{z}}, \mathrm{W} 2 \mathrm{R}, \mathrm{ERAM}\right]^{\mathrm{T}} \\
\overline{\mathrm{x}}_{\mathrm{a}}=[\mathrm{u}, \mathrm{v}, \mathrm{w}, \mathrm{p}, \mathrm{q}, \mathrm{r}, \phi, \theta, \psi, \mathrm{h}]^{\mathrm{T}}
\end{gathered}
$$

The outputs $\bar{y}_{\mathrm{ea}}$ and $\bar{y}_{\mathrm{a}}$ are a relevant subset of the available outputs. The airframe actuators, $\delta_{e_{1}}, \delta_{e_{r}}$, and $\delta_{r}$, are first order with bandwidths of $20 \mathrm{rads} / \mathrm{s}$, and they include rate and range limits. The nonlinear RCS model calculates the resultant RCS thrusts corresponding to each RCS nozzle area $\left(A L R_{R C S}, A_{R R}, A L Y_{R C S}, A R Y_{R C S}\right.$, and $\left.A P_{R C S}\right)$ on the basis of $\alpha$ and $\bar{q}, P E 3, T E 3$, and $P_{\text {amb }}$ as shown in figure 3. The RCS model also calculates the required RCS bleed mass flow rate, WB3. For the transition flight mode, WB3 is the primary airframe-to-engine coupling.

The propulsion system model that was used in the control evaluation comprised a nonlinear, component-level model (ref. 7) of the engine and nonlinear actuator and sensor models. Figure 4, from reference 8 , shows a schematic of the engine components and the station designations. The components are the low-pressure compressor (fan), the high-pressure compressor (HPC), the combustor, the highpressure turbine (HPT), the low-pressure turbine (LPT), and the exit areas(ventral and aft nozzle and ejectors). The flow for the aft and ventral nozzles and the primary flow for the ejectors are obtained from the mixing plane of the engine where the core and bypass flows mix as shown in figure 4. The secondary air for the ejectors is an entrained airstream that is external to the engine as displayed in figure 2. The two butterfly valve angles that control the primary airflow to the ejectors are commanded identically, so that no differential ejector thrusts are used in this study. The nonlinear engine model state comprised six variables: two rotor speeds (N2 and N25) and four component metal temperatures $\left(\mathrm{Tm}_{\mathrm{HPC}}\right.$, $\mathrm{Tm}_{\mathrm{PC}}, \mathrm{Tm}_{\mathrm{HPT}}$, and $\left.\mathrm{Tm}_{\mathrm{LPT}}\right)$. The metal temperatures have very slow dynamics and the rotor speeds dominate the engine dynamic response. The actuator models have delays and range and rate limits for the engine control inputs WF36, A8, ETA, A78, ANG79, and ANG8. Note in figure 3 that the subscript $\mathrm{L}$ indicates that these actuator commands have already been subjected to the engine limit protection scheme, which is part of the control to be discussed later. Although the HPC does have stator vanes, the vane angles are on an open-loop schedule, are not adjusted by the dynamic controller, and thus do not appear in figure 3 . Note that the WB3 that is calculated by the RCS model is limited as a percentage of the maximum engine core mass flow by limiting the commanded RCS nozzle areas. The sensor models for $\mathrm{T} 25, \mathrm{~N} 25, \mathrm{PS} 3$, and $\mathrm{DP} / \mathrm{P}$ are linear first-order lags with fixed time constants, except for T25, which has a time constant that is a function of W25. The engine model outputs $\bar{y}_{e}$ are N2, N25, FG9, FGE, FGV, T25, PS3, SM2, DP/P, W25, TE3, PE3, P6, T2, and P2, and $\bar{y}_{\mathrm{ea}}$ is the engine-to-airframe coupling vector as defined in equation (1). SM2 is not a measured output but is provided for evaluation of the engine response near the fan stall line. FG9, FGE, and FGV are used to evaluate the engine control, but the closed-loop system controls the estimated thrusts, which are discussed later. The vector $\bar{y}_{\text {ea }}$ acts as an input on the aircraft. The $\mathrm{x}-\mathrm{z}$ thrust components provide the necessary propulsive forces and moments. W2R and ERAM are used to calculate the inlet drag due to the engine mass flow and the inlet ram pressure recovery. 


\section{PROPULSION SYSTEM OPERATIONAL LIMITS}

Typical operational limits for a turbofan engine are the fan and core compressor surge margins, the maximum fan and core rotor speeds, the maximum fan turbine inlet temperature (FTIT), the maximum combustor pressure, and the maximum and minimum combustion fuel/air ratios. Of these limited variables, only the combustor pressure, the FTIT, and the rotor speeds are directly measurable. The FTIT measurement is not currently used for control because reliable measurements are lacking. The limits on the unmeasurable variables are reflected back onto the engine control inputs, resulting in input limit schedules that are a function of the measurable engine outputs. Two such limits are the fuel flow acceleration and deceleration (accel/decel) limit and the minimum fan surge margin limit.

The accel/decel schedule is a set of variable bounds on the fuel flow as a function of N25, T25, and P3. This limit schedule is determined a priori by using an open-loop nonlinear simulation of the engine. The schedule imposes a rate limit on core rotor speed as a function of the minimum and maximum fuel/air ratios (lean and rich blowout), the maximum turbine temperature, and the compressor surge margin, as shown in figure 5, from reference 9 . The accel/decel limit is reflected back on the engine control input by imposing a limit schedule on the fuel/air ratio. The fuel/air ratio is a function of the WF 36/P3 ratio because the HPC discharge pressure is indicative of the combustor air mass flow rate. The accel/decel schedule is implemented as minimum and maximum bounds on the WF 36/P3 ratio as a function of the corrected core rotor speed, N25R. An example turbofan engine limit schedule from reference 10 shows a normalized WF36/P3 ratio as a function of N25R in figure 6. In figure 6 the $\alpha_{1}$ "droop lines" are lines of constant engine thrust for fixed inlet conditions. The rotor speed schedule determines the "steady state line." A typical engine acceleration from $\alpha_{1}$ to $\alpha_{2}$ is shown in figure 6. Note how the normalized WF36/P3 ratio increases at nearly constant rotor speed because of the rotor speed lag. Once the accel limit is reached, WF36/P3 follows the accel limit until the desired thrust setting is obtained. Finally, WF36/P3 settles down until the steady-state line is reached. Note that when WF36/P3 is determined by the accel limit, the fuel flow is determined by the engine outputs, P3 and N25R. The feedback of these variables links the rate of change of fuel flow (WF 36 ) to the rate of change of the core rotor speed (N25) whenever the fuel flow limit is encountered. Thus, the accel/decel limit defines the large-perturbation performance of the engine (assuming no special thrust wasting or off-design schedule engine operating mode). Other limits, such as the maximum fan speed and the minimum combustor pressure, also affect fuel flow, but they were not found to be critical during the transition flight mode and are not considered herein.

The minimum fan surge margin is another critical limit in turbofan engines. Figure 7, from reference 11, shows how the fan surge margin decreases during engine deceleration for a turbofan engine with an appropriately scheduled nozzle area. During a gross thrust decrease on a turbofan engine the surge margin decreases quickly as the fan pressure ratio increases. With the surge margin limited, the much slower fan rotor speed follows along the surge limit line until the desired operating point is reached. The surge margin cannot be directly measured, but it can be correlated with a function of the "delta P over P" pressure ratio (DP/P) as discussed briefly in references 11 and 12 . Therefore, it is possible to limit the fan surge margin by limiting $\mathrm{DP} / \mathrm{P}$. Imposing a limit schedule on the minimum value of $\mathrm{DP} / \mathrm{P}$ imposes a varying minimum value on the total engine flow exit area. If the total exit area decreases too quickly, backpressure builds up across the fan and DP/P drops. The limit protection scheme will then increase the total exit area to keep $\mathrm{DP} / \mathrm{P}$, and thus the fan surge margin, above the minimum value. In a multinozzle engine all the nozzles contribute to the total area, and they all have an effect on the fan surge margin through the bypass duct as can be seen in figure 4. The distribution of the limit protection total area increase over the available nozzles is part of the integrated control design. 
The linear integrated control design has been discussed in detail in reference 3 , but the propulsion specifications in the integrated control design are discussed here. Before setting up the "design plant"

(i.e., the linear model used in the $H_{\infty}$ design, which in reference 3 included scalings, frequency weights, and internal noise models to build in robustness to specific uncertainties), an open-loop analysis was performed on the system models. In order to gain an understanding of the limit operation of the propulsion system, an open-loop analysis was performed on the engine model with the limit protection scheme in place, as shown in figure 8 . From this open-loop analysis it was determined how close the nominal operating point was to the limits, to what extent the actuators could be used before limits were imposed, and what gross effect the limits have on the thrust response (i.e., the region of validity of the small-perturbation linear engine model was determined relative to the operational limits). This information was used in selecting the weights that were used in the linear integrated design. For example, at the design point the accel schedule was reached when the fuel flow was stepped by approximately $600 \mathrm{lbm} / \mathrm{hr}$. The maximum fuel flow available is in the tens of thousands. Using $1000 \mathrm{lbm} / \mathrm{hr}$ for scaling the fuel flow in the integrated design instead of the maximum value possible reduced the probability that the fuel flow limit schedule would be encountered. Similarly, when a first-order model was selected to represent the fuel flow actuator in the linear design plant, the bandwidth of this model was based on the phase response of the nonlinear actuator because fuel flow has a significant phase lag due to the fuel transportation delay. This open-loop analysis of the propulsion model with the limit protection scheme in place documented the small- and large-perturbation thrust response of the engine. The engine still encounters limits whenever large thrust changes are requested and thus limit protection is still required, but using this information in the integrated control design develops a system that only encounters the engine limits for large-perturbation pilot inputs. Examples of typical, large-perturbation pilot inputs that drive the propulsion system into the limits are discussed shortly.

\section{DESCRIPTION OF ENGINE CONTROLLER}

Application of step 2 in the IMPAC methodology (linear integrated control design) resulted in a linear, time-independent, state-space controller at the design point (ref. 4). Applying step 3 (controller partitioning) resulted in the partitioning of the linear centralized controller into lateral and longitudinal controllers. The longitudinal controller was specified to have a hierarchical structure composed of a longitudinal airframe controller and an engine controller. The longitudinal airframe controller calculates three thrust commands that are tracked by the propulsion control. The partitioned propulsion control is completely separate from the airframe controller. This is important so that engine manufacturers can benchtest the propulsion control system independently of the airframe and airframe controller.

The details of the overall engine controller that is built around the partitioned, linear controller are shown in figure 9. The linear partitioned engine controller is of the form

$$
\dot{\bar{x}}_{\mathrm{ec}}=\mathbf{A}_{\mathrm{ec}} \overline{\mathbf{x}}_{\mathrm{ec}}+\mathbf{B}_{\mathrm{ec}} \overline{\mathrm{y}}_{\mathrm{ec}} ; \quad \overline{\mathrm{u}}_{\mathrm{ec}}=\mathbf{C}_{\mathrm{ec}} \overline{\mathbf{x}}_{\mathrm{ec}}+\mathbf{D}_{\mathrm{ec}} \overline{\mathrm{y}}_{\mathrm{ec}}
$$

where $\bar{y}_{e c}, \bar{u}_{e c}$, and $\bar{x}_{e c}$ are the perturbed engine controller input, output, and state vectors; the first two are described here:

$$
\begin{gathered}
\bar{y}_{\mathrm{ec}}=\left[\mathrm{e}_{\mathrm{N} 2}, \mathrm{e}_{\mathrm{FG} 9}, \mathrm{e}_{\mathrm{FGE}}, \mathrm{e}_{\mathrm{FGV}}, \mathrm{N} 2, \mathrm{WB} 3_{\mathrm{est}}\right]^{\mathrm{T}} \\
\overline{\mathrm{u}}_{\mathrm{ec}}=\left[\mathrm{WF} 36_{\mathrm{c}}, \mathrm{A} 8_{\mathrm{c}}, \mathrm{ETA}_{\mathrm{c}}, \mathrm{A78}{ }_{\mathrm{c}}\right]^{\mathrm{T}}
\end{gathered}
$$


The longitudinal airframe controller commands thrusts from the three nozzles, FG9 ${ }_{c}, \mathrm{FGE}_{\mathrm{c}}$, and $\mathrm{FGV}_{\mathrm{c}}$. The engine controller uses these commands to determine the fan speed command that is based on the fan speed schedule. The controller then regulates $\mathrm{N} 2$ and the three thrusts. Thrust is not measured directly, but a nonlinear estimator is used to estimate the three thrusts. As shown in figure 9 the inputs to the thrust estimator are the sensed values for the actuators WF 36, A8, ETA, and A78, the engine outputs P6, N2, DP/P, T2, and P2, the estimated RCS bleed flow WB3 ${ }_{\text {est }}$, and $\mathrm{P}_{\text {amb. We are using }}$ the nonlinear RCS model to generate WB3 ${ }_{\text {est }}$. The error between the estimated thrust and the thrust computed by the engine model is less than 3 percent of the engine model thrust for both steady-state and dynamic values. This error can be large in terms of perturbation quantities for a linear system. Because the engine controller tracks the commanded thrusts with estimated thrusts, it is important to ensure that thrust estimation errors do not lead to degradation in the integrated system performance.

The partitioned linear controller yielded good small perturbation performance, but even with the scaling in the design plant to help distribute the control authority in order to avoid the engine limits, it was known early in the design that the engine will encounter limit operation in order to meet the extremes of the integrated system performance. The limit protection scheme and the accompanying integrator windup protection scheme are discussed in the next section.

\section{IMPLEMENTATION OF PROPULSION CONTROL LIMIT OPERATION}

The two primary engine limits that are encountered in the transition mode are the accel schedule for the fuel flow and the fan surge margin. The accel schedule and fan surge margin limit protection schemes from reference 13 were implemented as engine limit schedules, shown as a block in figure 9. The accel/decel schedule is similar to the scheme for the F100 engine that was previously described. The scheme for protecting the fan surge margin is implemented as previously discussed, by limiting the minimum value for $\mathrm{DP} / \mathrm{P}$. If the $\mathrm{DP} / \mathrm{P}$ limit is reached, all of the nozzle areas are opened by a percentage of their contribution to the total nozzle area. Thus, the fan surge margin limit is shared over all three nozzles (aft, ventral, and ejectors), and all three thrusts are affected when the fan surge margin is reached. Alternative fan surge margin protection schemes that take advantage of redundancies in the pitch control of the airframe are possible but have not yet been investigated.

When the outputs of a controller are limited, the controller integrator must be constrained to prevent integrator windup. Windup is defined as an open-loop, unbounded increase in the magnitude of a controller integrator that does not manifest itself as an increase in the magnitude of the value of the actuator that is seen by the airframe. There is a disconnect between the value calculated by the control and the actuator-commanded value. In the control literature, little attention has been given to developing integrator windup protection schemes for general multivariable controllers. However, reference 13 does a good job of pulling together many of the existing antiwindup schemes. The following discussion is based on the general antiwindup and bumpless transfer (AWBT) scheme discussed in reference 13. Figure 10 is a detailed block diagram of the implementation of the "tracking mode" version of the AWBT scheme. The AWBT action is based on modifying the controller state variable by using the difference between the limited and the commanded actuator values, $\mathbf{e}_{\mathbf{u}}=\mathrm{u}_{\mathrm{eL}}-\mathrm{u}_{\mathrm{ec}}$, such that the modified controller outputs track the limited actuator values. The integrator windup protection gain matrix $\mathbf{\Lambda}$, is defined as $\mathbf{\Lambda}=\lambda \mathbf{C}_{\mathrm{ec}}^{*}$, where $\mathbf{C}_{\mathrm{ec}}^{*}$ is the pseudoinverse of $\mathbf{C}_{\mathrm{ec}}$. The modified controller then has the form

$$
\begin{gathered}
\dot{\mathrm{x}}_{\mathrm{ec}}=\mathbf{A}_{\mathrm{ec}} \mathrm{x}_{\mathrm{ec}}+\mathbf{B}_{\mathrm{ec}} \mathrm{y}_{\mathrm{ec}}+\Delta \mathrm{e}_{\mathrm{u}} \\
\mathrm{u}_{\mathrm{ec}}=\mathbf{C}_{\mathrm{ec}} \mathrm{x}_{\mathrm{ec}}+\mathrm{D}_{\mathrm{ec}} \mathrm{y}_{\mathrm{ec}}
\end{gathered}
$$


By using the definition of $e_{u}$, the modified controller state equation can be written as

$$
\dot{\mathbf{x}}_{\mathrm{ec}}=\left(\mathbf{A}_{\mathrm{ec}}-\lambda \mathbf{C}_{\mathrm{ec}}^{*} \cdot \mathbf{N} \cdot \mathbf{C}_{\mathrm{ec}}\right) \mathrm{x}_{\mathrm{ec}}+\left(\mathbf{B}_{\mathrm{ec}}-\lambda \mathbf{C}_{\mathrm{ec}}^{*} \cdot \mathbf{N} \cdot \mathbf{D}_{\mathrm{ec}}\right) \mathrm{y}_{\mathrm{ec}}+\mathbf{\Lambda} \mathrm{u}_{\mathrm{eL}}
$$

where $\mathbf{N}$ is a diagonal matrix of ones and zeros with the ones corresponding to a limited actuator and the zeros corresponding to the unlimited actuators. For this example, a one in the $(1,1)$ element of the $\mathrm{N}$ matrix would indicate that the fuel flow was limited. Similarly, ones in the $(2,2),(3,3)$, and $(4,4)$ elements would indicate that the fan surge margin limit was encountered. Ideally, the product $\mathbf{C}_{\mathbf{e c}}^{*} \cdot \mathbf{N} \cdot \mathbf{C}_{\mathbf{e c}}$ results in a diagonal matrix, and the scalar value $\lambda$ is used to push the diagonal elements of the modified controller A matrix farther into the left half-plane. This AWBT action results in a mode switch, so that the controller now regulates the actuator command at the limited actuator value while maintaining the original control objectives of tracking the specified commands. Because $\mathbf{C}_{e c}$ is not an invertible square matrix, it is not possible to speed up all of the engine controller poles. No detailed analyses on the robustness of this AWBT scheme have yet been performed.

To demonstrate the effect of integrator windup protection (IWP), figure 11 compares the response of the closed-loop propulsion system with and without the integrator windup protection for an large FG9 step command. This $\mathrm{FG}_{\mathrm{c}}$ request encounters a hard fuel flow limit because it requests more than the maximum thrust that the engine can deliver. Figure 11(a) shows the steady-state error that develops in FG9 when the hard limit is encountered. Figure 11(b) shows the corresponding limited fuel flows (WF $36_{\mathrm{L}}$ ) for the two cases and the WF36 ${ }_{c}$ that is commanded by the linear controller for the case without integrator windup protection (without IWP). Note how WF 36 grows unbounded whereas the actuator response is limited. When $F G 9_{c}$ returns to the initial value, the system without IWP takes longer to come off the limit, as shown in figure 11(b), owing to the time taken by the controller integrator to unwind. This delays the FG9 response and also increases the coupling to the other nozzles as shown by the FGV response in figure 11(c). In summary, the AWTB scheme offers good limit tracking while keeping the regulated variables near the commanded values for a variety of inputs.

\section{PERFORMANCE EVALUATION RESULTS FOR PILOT INPUTS}

Several representative pilot inputs were used to evaluate the performance of the integrated system in the presence of the engine operation limits. In the transition flight mode, typical pilot control tasks are acceleration or deceleration to a desired airspeed while maintaining flightpath angle or change to a desired flightpath angle while maintaining airspeed. The response of the closed-loop system consisting of the airframe plus engine model as shown in figure 3, the engine controller as shown in figure 10, and the airframe flight controller as described in reference 4 is discussed in the following. An emphasis is placed on comparing the system responses with and without active engine limit protection.

Figure 12 shows the vehicle response to a pilot-commanded deceleration of $0.2 \mathrm{~g}$ 's to decrease the forward velocity by $20 \mathrm{ft} / \mathrm{s}$. Note that velocity responses for the limited (limit protection active) and unlimited (limit protection disabled) systems are very similar as shown in figure 12(a). For the case with limit protection active, WF36 rides the accel schedule for the interval from $3 \mathrm{~s}$ to $8 \mathrm{~s}$ as shown in figure 12(b). For the case with limit protection disabled, WF36 actually exceeds the corresponding accel schedule for an interval from $3 \mathrm{~s}$ to $5 \mathrm{~s}$. Note that the accel schedule is different for the limits-active and limits-disabled cases because it is based on the engine outputs, which are different for the two cases. Figure 12(c) shows that the case with limit protection active does have slightly more coupling in the flightpath angle, which is due to the difference in the FGV responses shown in figure 12(d). In both cases the 
fan surge margin limit is not reached. The response is interesting in that the deceleration of the airframe has an end result of "accelerating" the engine. Note that the fuel flow is initially reduced to reduce the aft nozzle thrust but is then increased to increase the ejector and ventral nozzle thrusts in order to compensate for the lost aerodynamic lift.

Figure 13 shows the airframe and engine responses to a $4^{\circ}$ commanded increase in flightpath angle. This command is essentially a vertical lift command and requires a large increase in thrust. Figures 13(a) to (c) compare the airframe response for a controller with and without active limit protection. The flightpath and velocity responses are very close in the two cases. There is a slight increase in the pitch coupling with the limit protection active, but the response in both cases shows good decoupling from flightpath command. Figure 13(d) shows the engine fuel flow responses for the same command. The system with limit protection rides the accel schedule for the interval from $0.2 \mathrm{~s}$ to $2.2 \mathrm{~s}$. The encounter with the accel schedule also slows the fan speed response relative to the case with no limit protection, but the steadystate fan speed schedule is maintained. The nominal operating point is such that on this maneuver the fan surge margin limit is only touched briefly around $2 \mathrm{~s}$. The unlimited case does exceed the fan surge margin limit. Figure 14 compares the airframe-commanded, estimated, and actual (engine CLM output) ejector thrust responses to the flightpath command for the system with limit protection active. In this figure the steady-state bias between the actual and estimated or commanded thrusts has been removed so that at time zero all the perturbed thrusts are zero. Note that while there is some mismatch between the actual and estimated thrust, the airframe responses shown in figure 13 are not adversely affected.

\section{SUMMARY OF RESULTS}

This paper describes the propulsion-system-specific results of a closed-loop integrated flight and propulsion control system that resulted from using the integrated methodology for propulsion and airframe control design method. A brief review of the methodology was given along with a discussion of how the propulsion system specifications appear in the integrated design. The operational limits for turbofan engines were discussed, and a limit protection scheme and a multivariable, integrator windup protection scheme were demonstrated in simulation. Simulated, closed-loop, time history responses demonstrated that the engine limit protection can be wrapped around the partitioned linear engine controller without adversely affecting the integrated system response to appropriate pilot-commanded inputs for the transition flying task.

\section{REFERENCES}

1. Gal-Or, B.: Vectored Propulsion, Supermaneuverability and Robot Aircraft. Springer-Verlag, New York, 1990.

2. Garg, S., et al.: IMPAC-An Integrated Methodology for Propulsion and Airframe Control. NASA TM-103805, 1991.

3. Garg, S.; and Ouzts, P.J.: Integrated Flight/Propulsion Control Design for a STOVL Aircraft Using H-Infinity Control Design Techniques. NASA TM-104340, 1991.

4. Garg, S.; and Mattern, D.L.: Application of an Integrated Flight/Propulsion Control Design Methodology to a STOVL Aircraft. AIAA Paper 91-2792, 1991. 
5. Garg, S.: Controller Partitioning for Integrated Flight/Propulsion Control Implementation.

Presented at the 1992 American Control Conference, Chicago, IL, June 1992.

6. Akhter, M.M., et al.: Simulation Development for U.S./Canada ASTOVL Controls Technology Program. Proceedings of the Twentieth Annual Pittsburgh Conference on Modeling and Simulation, W.C. Vogt and M.H. Mickle, eds., Instrument Society of America, Research Triangle Park, NC, 1989.

7. Drummond, C.K.; and Ouzts, P.J.: Real-Time Simulation of a STOVL Turbofan Engine. NASA TM-102409, 1989.

8. Adibhatla, S., et al.: GE Aircraft Engines STOVL Multivariable Propulsion Control. General Electric, Cincinnati, OH, 1989.

9. Sobey, A.J.; and Suggs, A.M.: Control of Aircraft and Missile Powerplants. An Introduction to the Analysis and Design of Engine Control Systems. John Wiley \& Sons, Inc., New York, 1963, p. 185.

10. Arpasi, D.J.; Cwynar, D.S.; and Wallhagen, R.E.: Sea-Level Evaluation of Digitally Implemented Turbojet Engine Control Functions. NASA TN D-6936, 1972.

11. F100 Multivariable Control Synthesis Program, Volume 1-Development of F100 Control System. Report AF APL-TR-77-35-VOL-1. Systems Control, Inc., Palo Alto, CA, 1977.

12. Beattie, E.C.: Control Mode Studies for Advanced Variable-Geometry Turbine Engines. Report AF APL-TR-75-7, Air Force Aero-Propulsion Laboratory, Pratt \& Whitney Aircraft, East Hartford, CT, 1974, pp. 13-15.

13. Campo, P.J.; Morari, M.; and Nett, C.N.: Multivariable Anti-Windup and Bumpless Transfer: A General Theory. Proceedings of the 1989 American Control Conference, Vol. 2, AIAA, New York, 1989, pp. 1706-1711. 


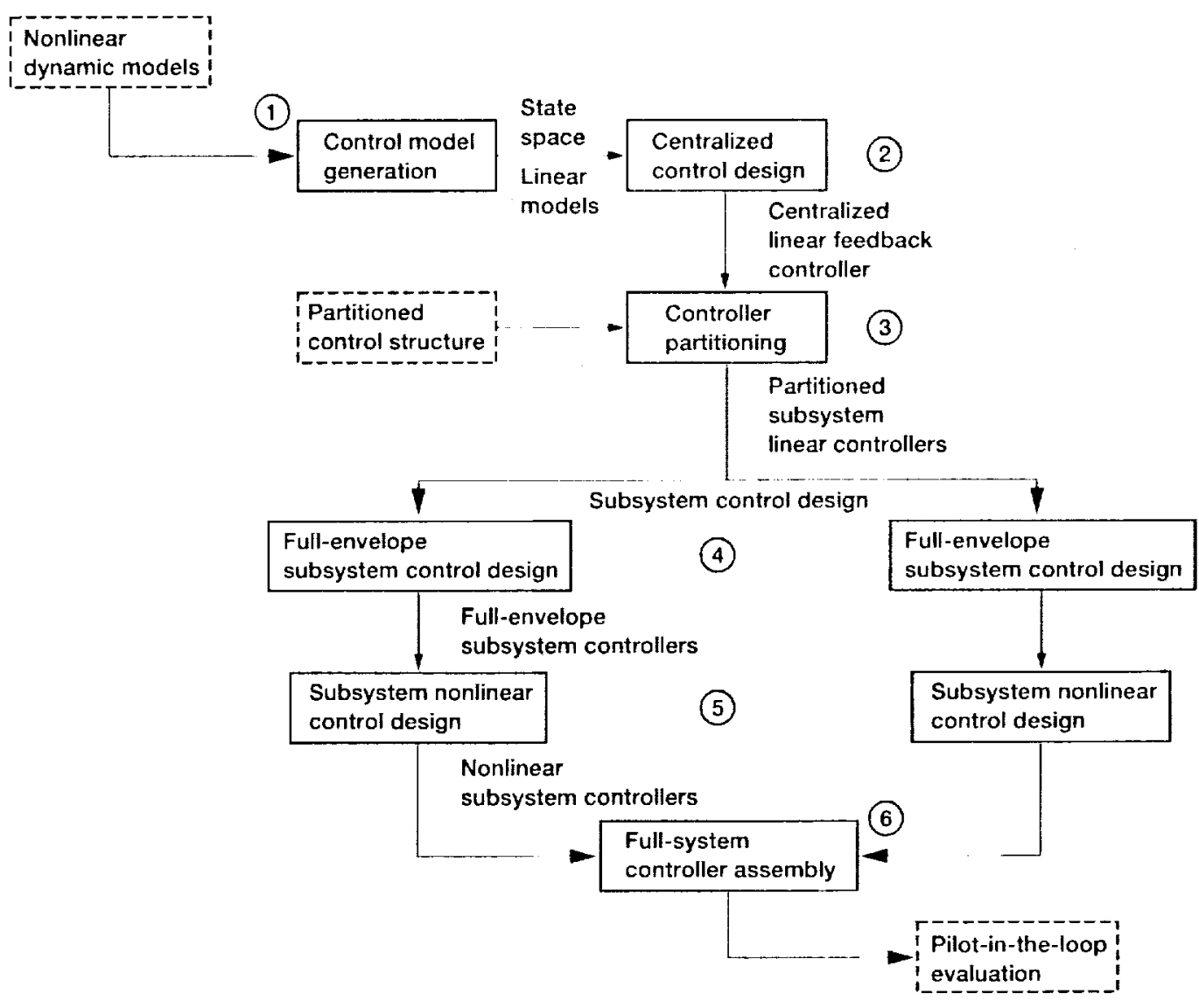

Figure 1.-IMPAC methodology flowchart. 


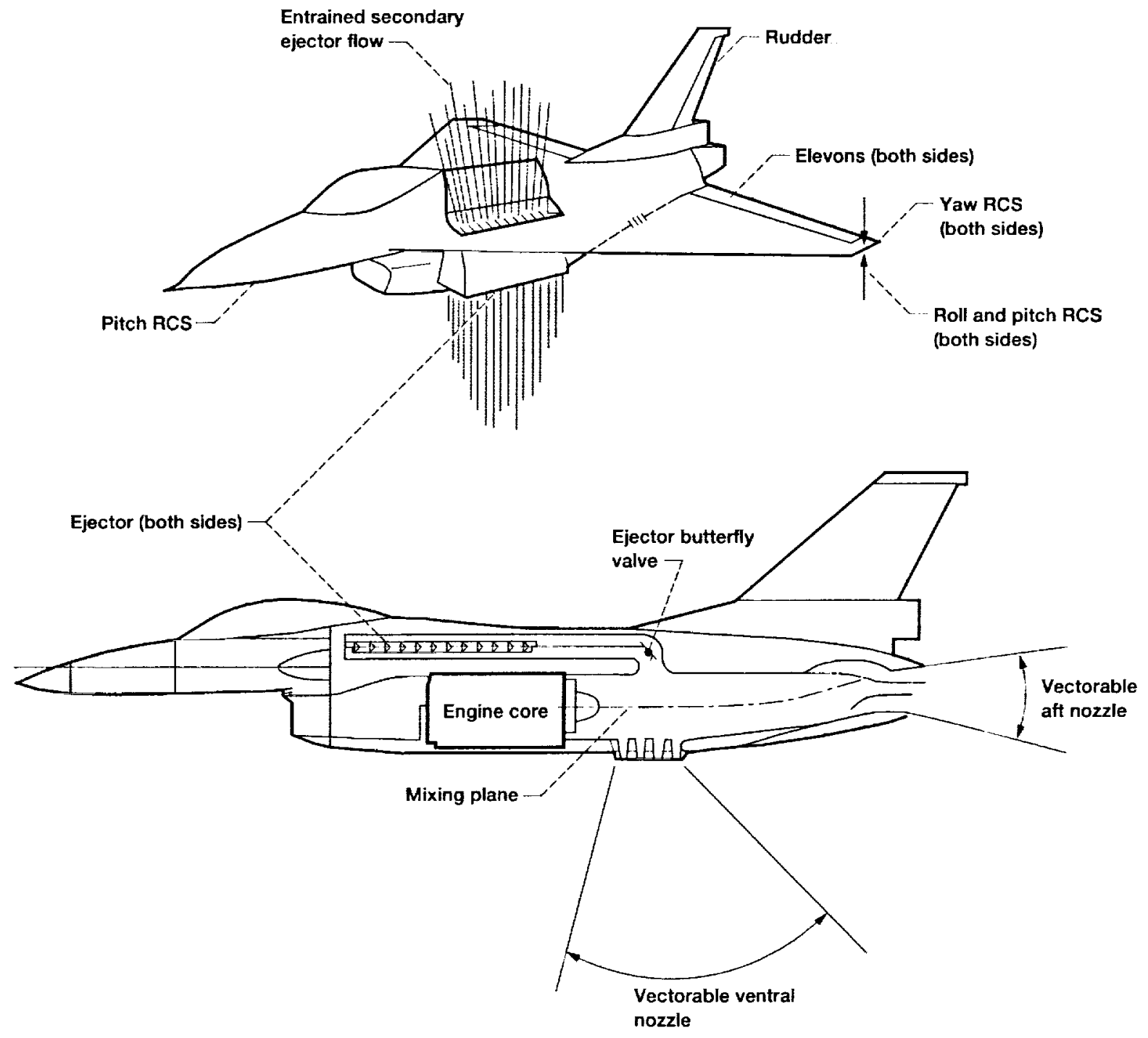

Figure 2.-STOVL aircraft configured with ejectors. 


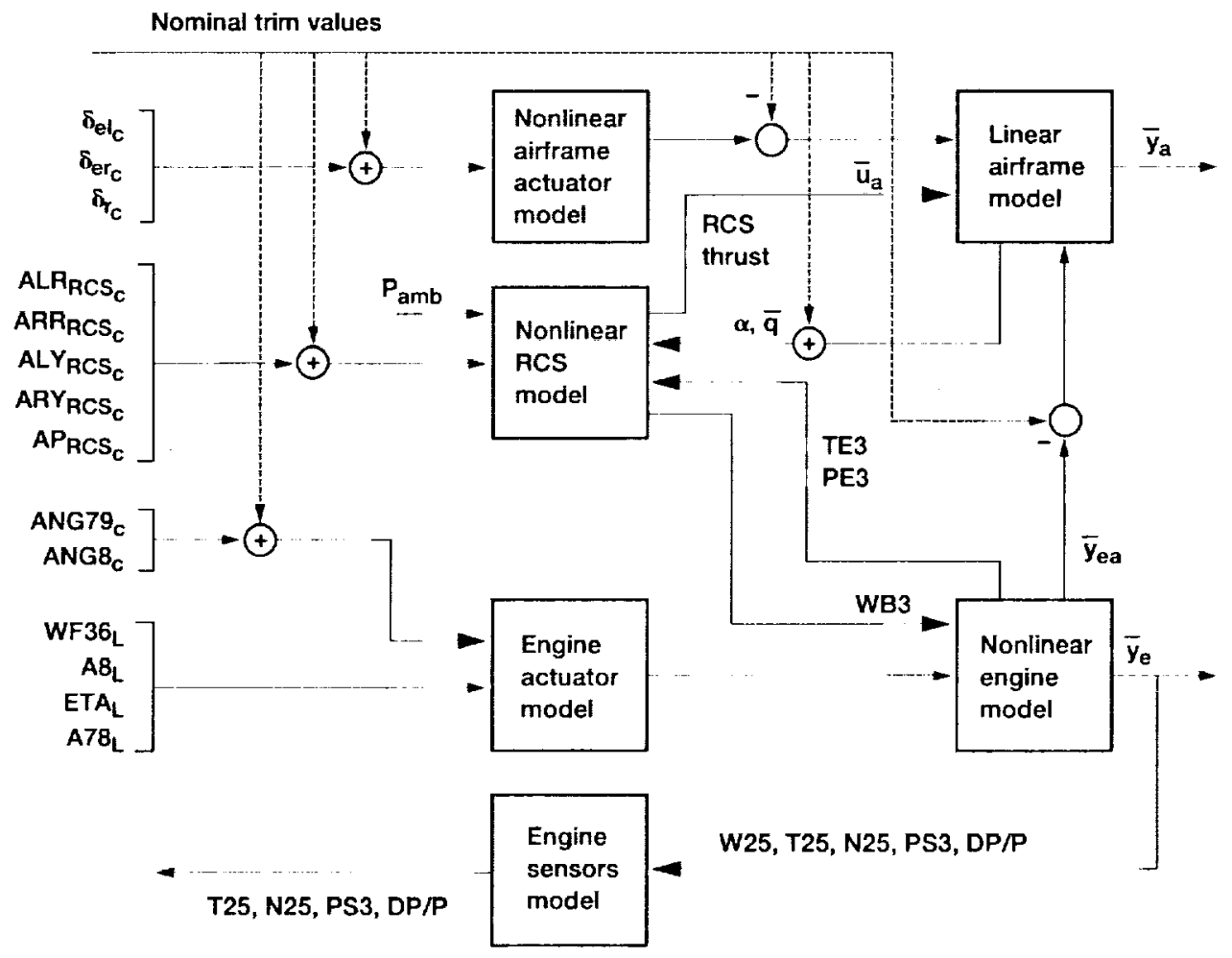

Figure 3.-Overall block diagram of nonlinear model.

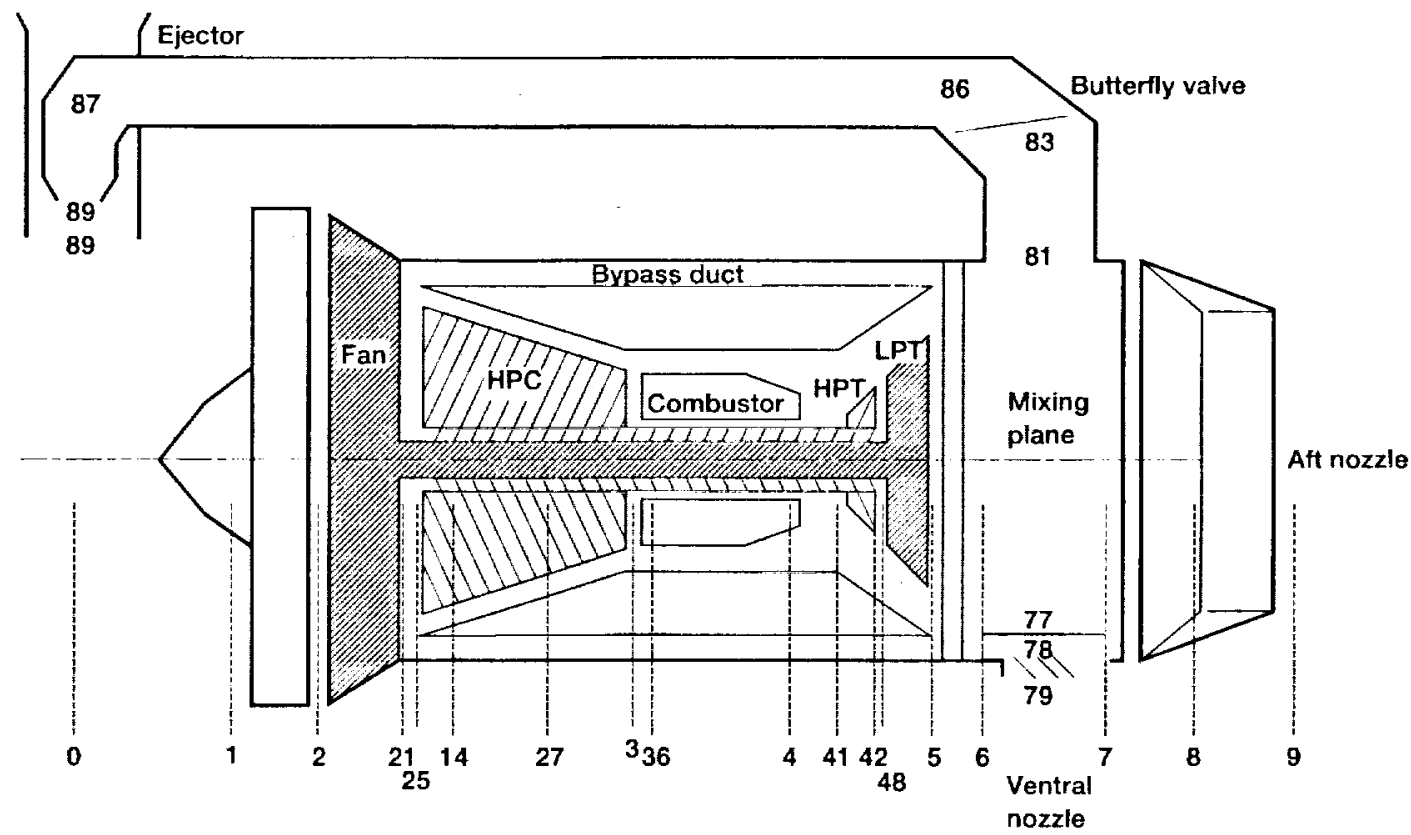

Figure 4.-Schematic of turbofan engine showing station designations. From reference 8. 


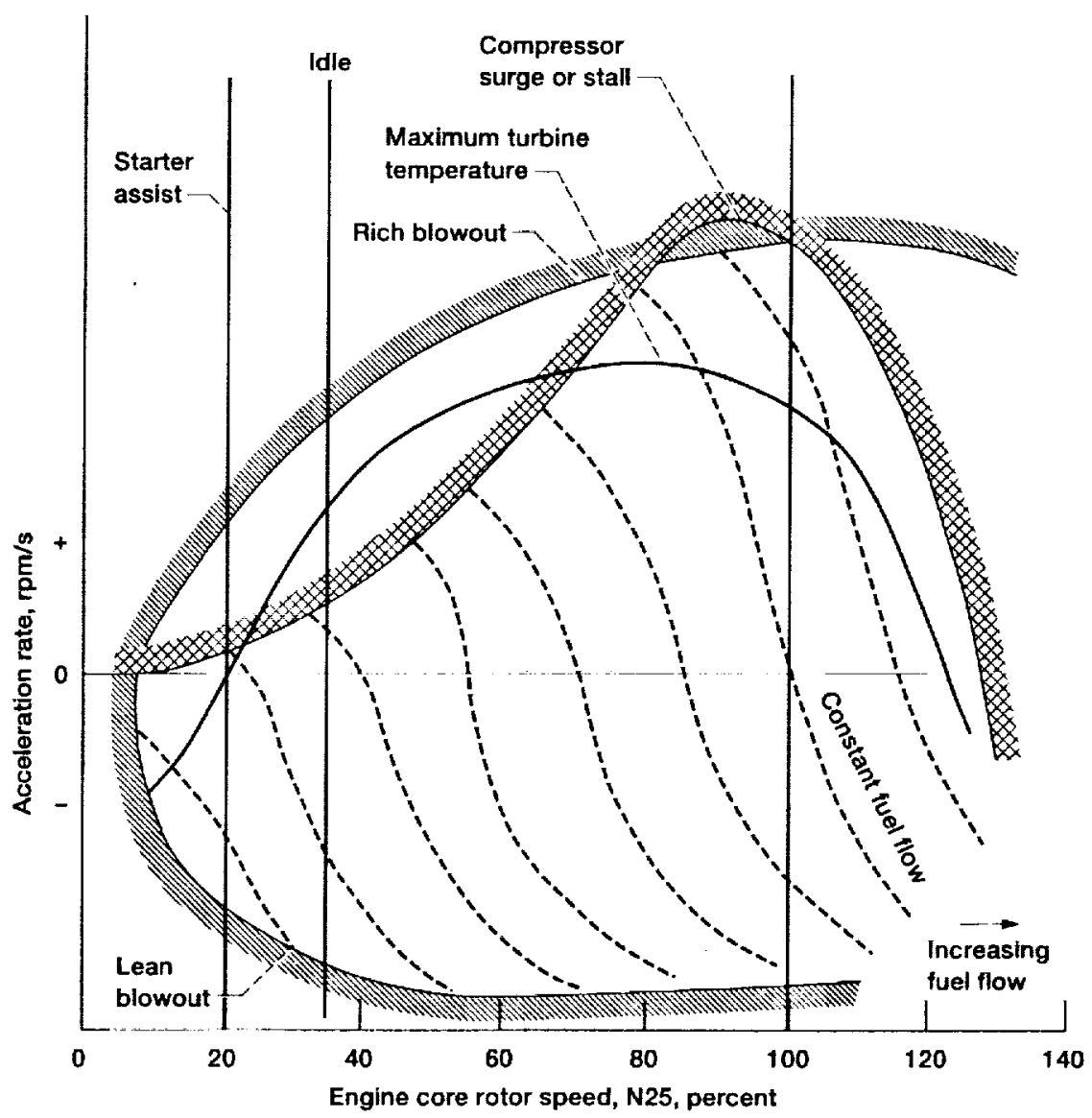

Figure 5.-Typical turbojet acceleration limits. From reference 9.

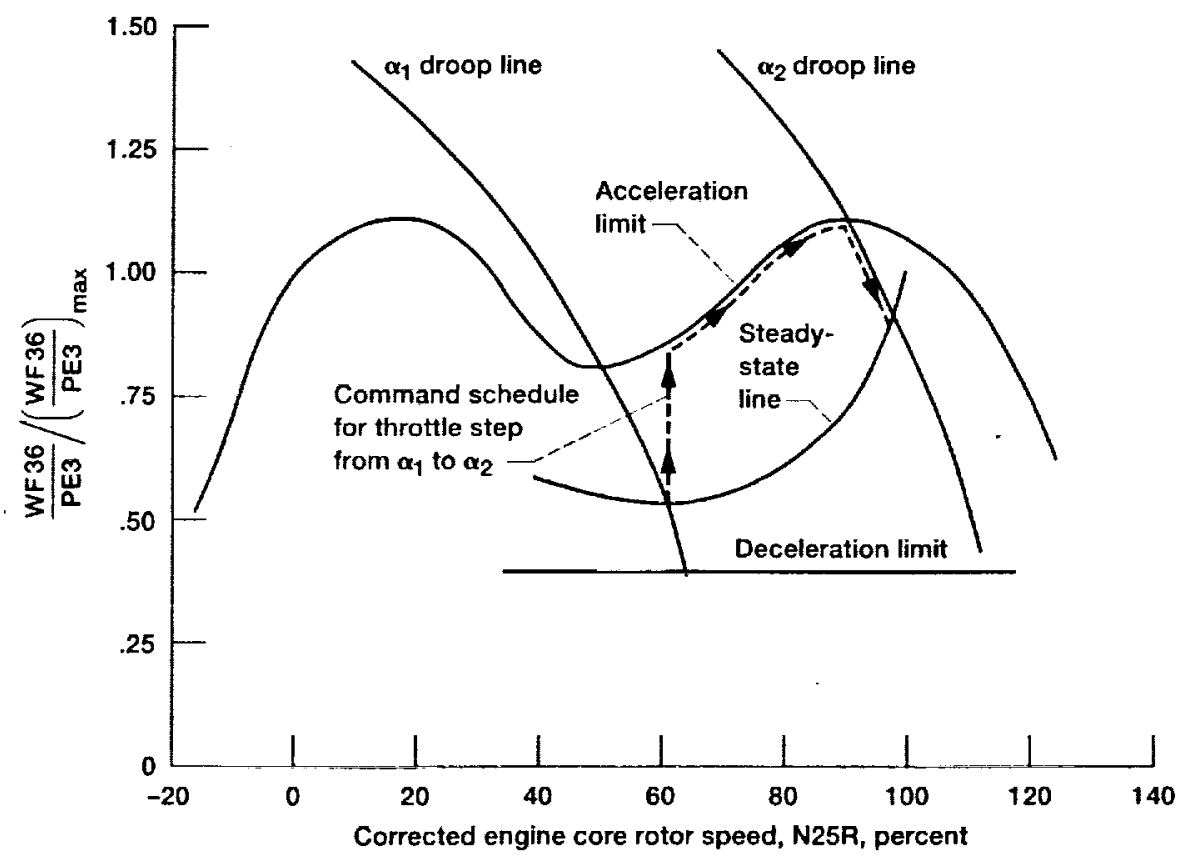

Figure 6.-Typical engine fuel control operating map showing acceleration and deceleration limits. From reference 10 . 


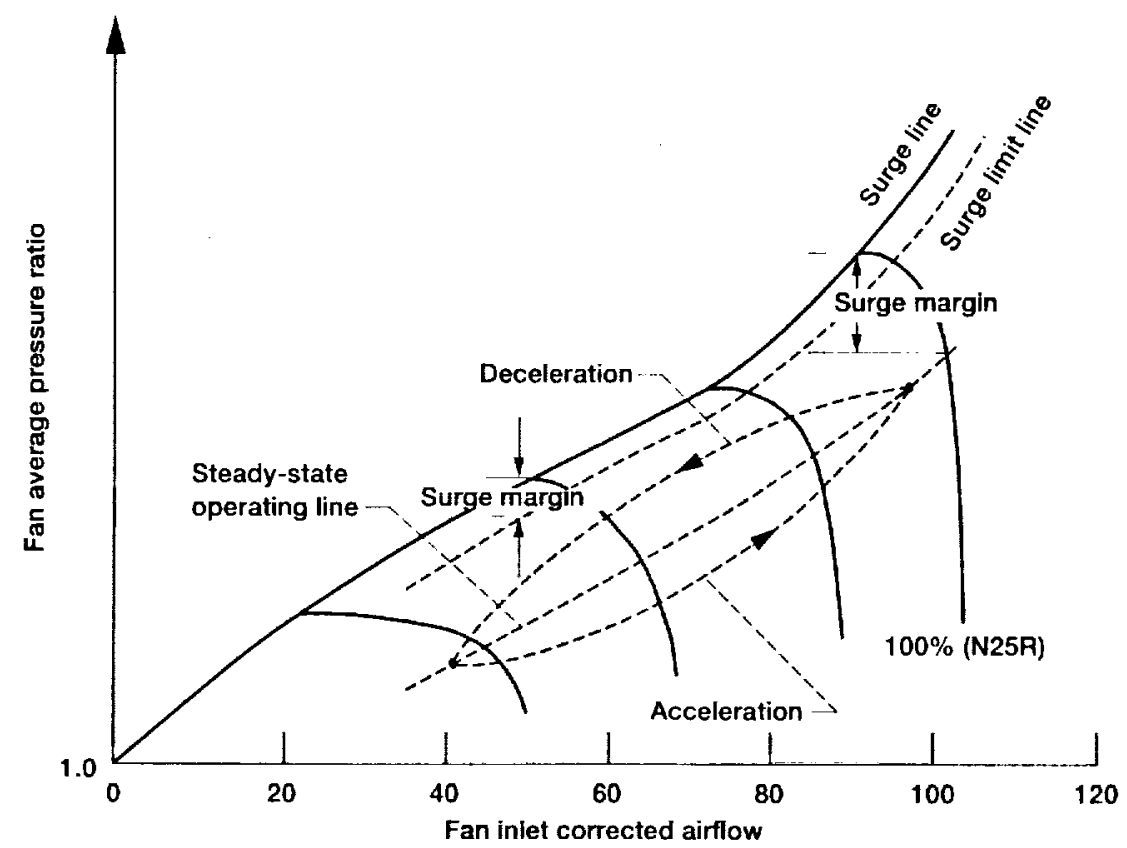

Figure 7.-Fan surge margin change during transient (F100 engine with scheduled nozzle area). From reference 11.

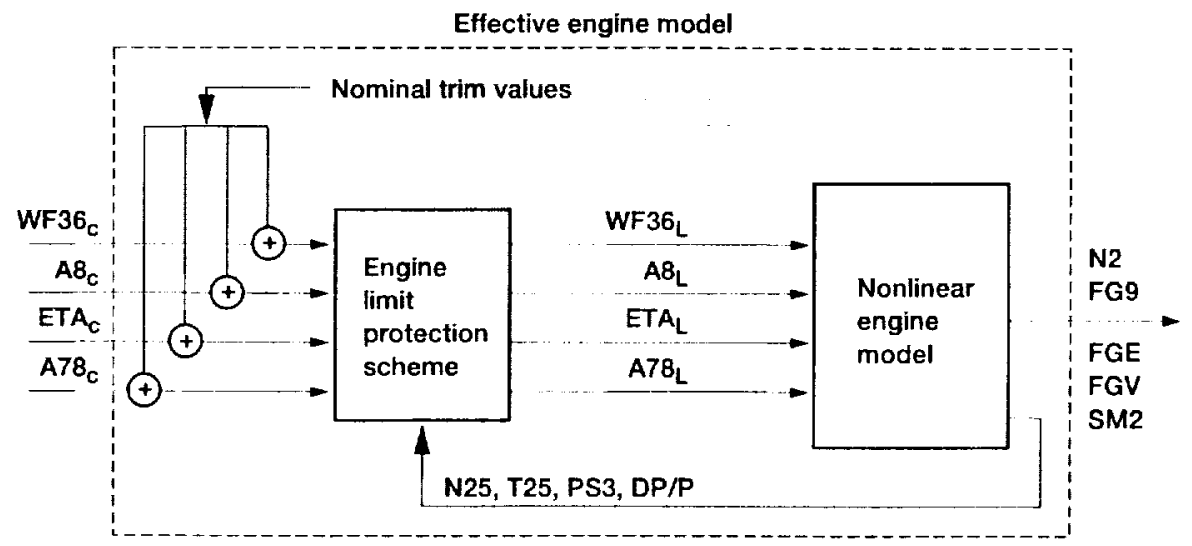

Figure 8.-Open-loop analysis of propulsion system with limits. 


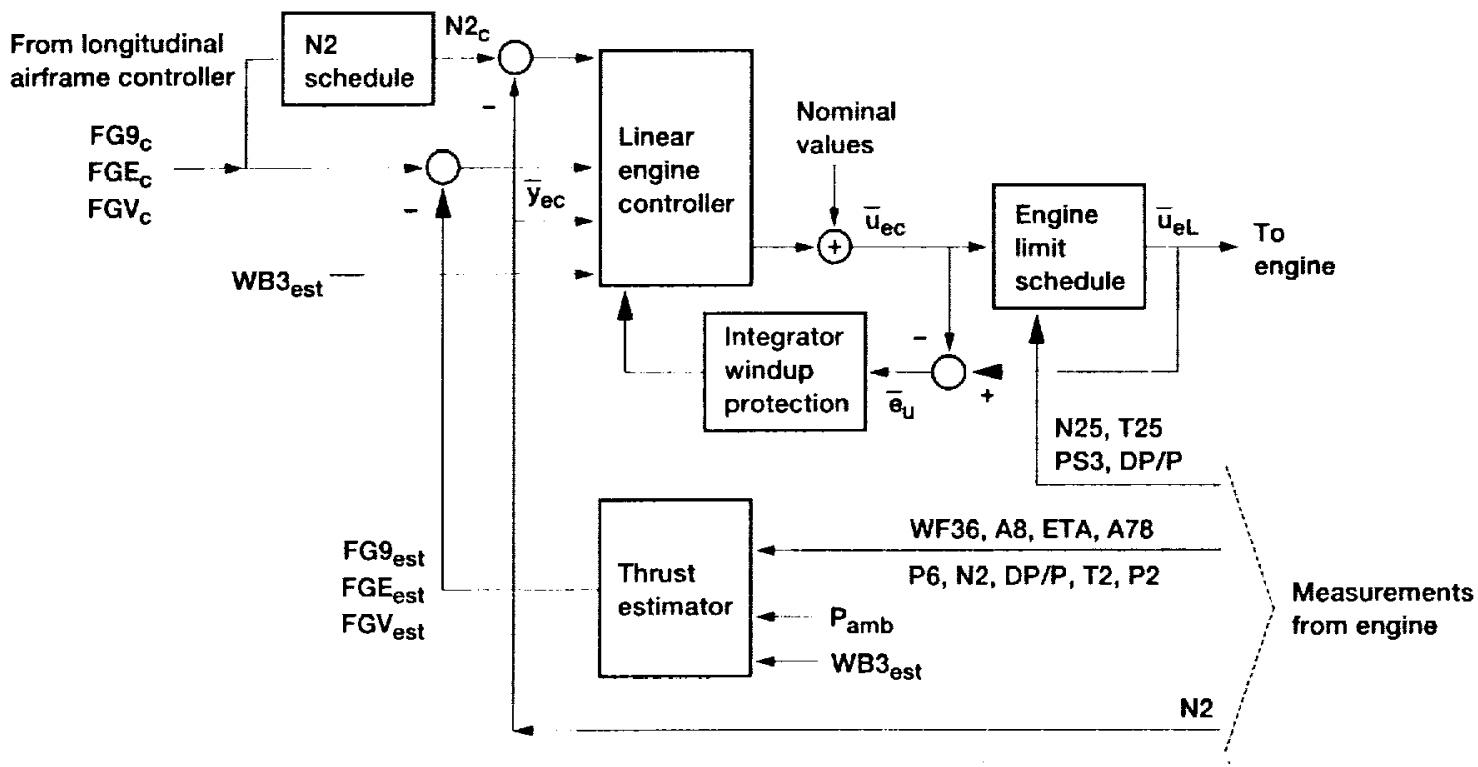

Figure 9.-Detailed block diagram of engine controller.

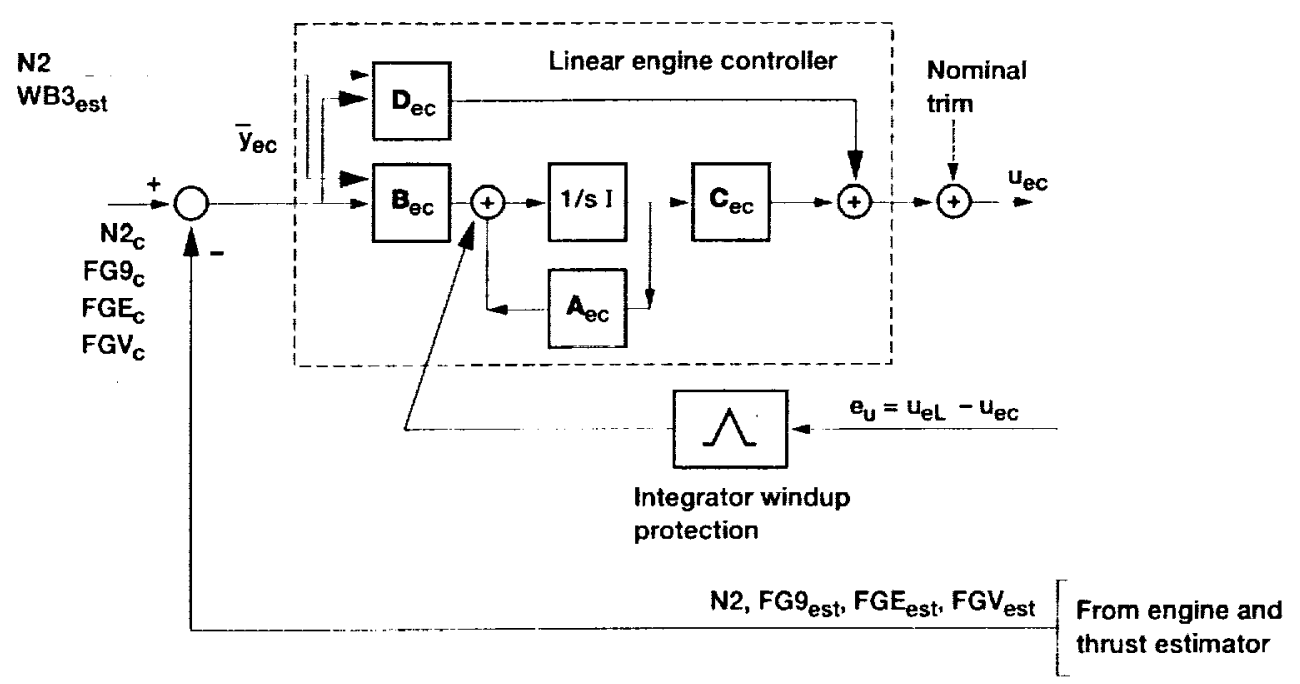

Figure 10.-Detailed block diagram of limit and integrator windup protection. 


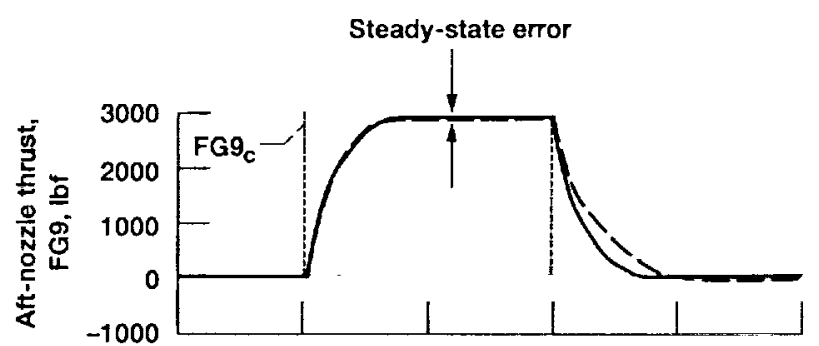

(a) Steady-state error.

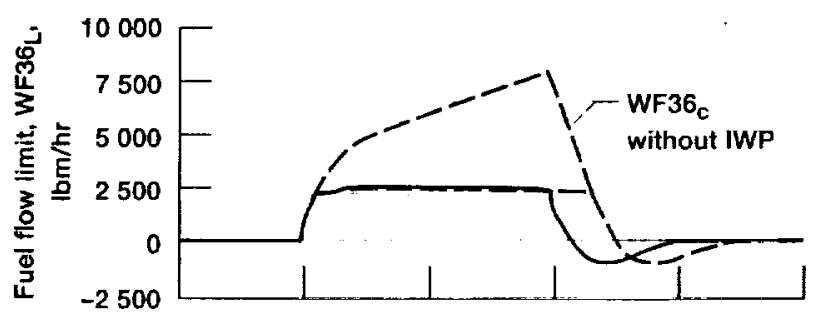

(b) Corresponding limited fuel flows.

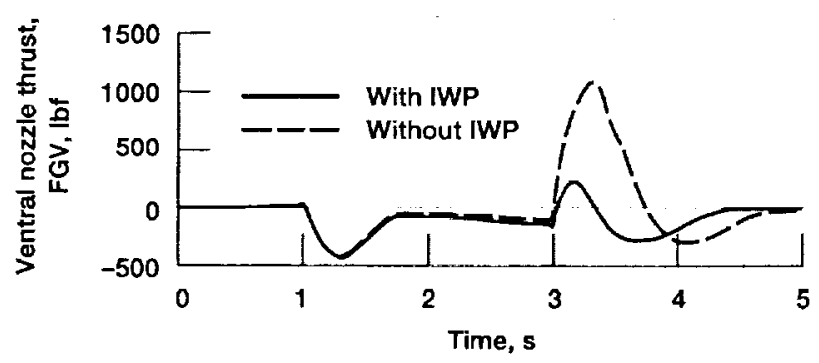

(c) FGV response.

Figure 11.-Effects of integrator windup protection for a 3000-lbf step thrust command.

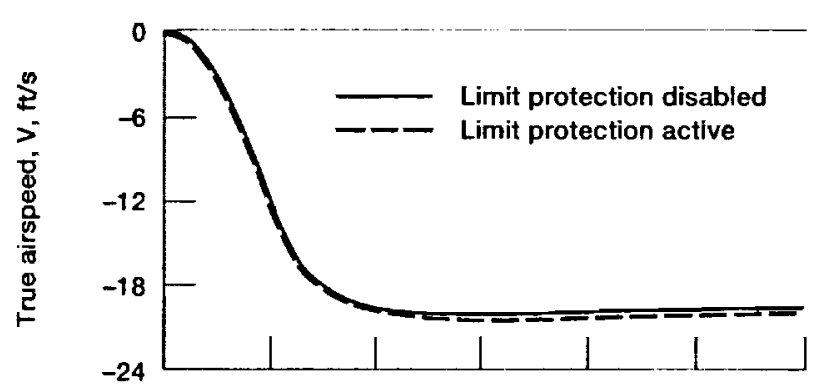

(a) Velocity response.

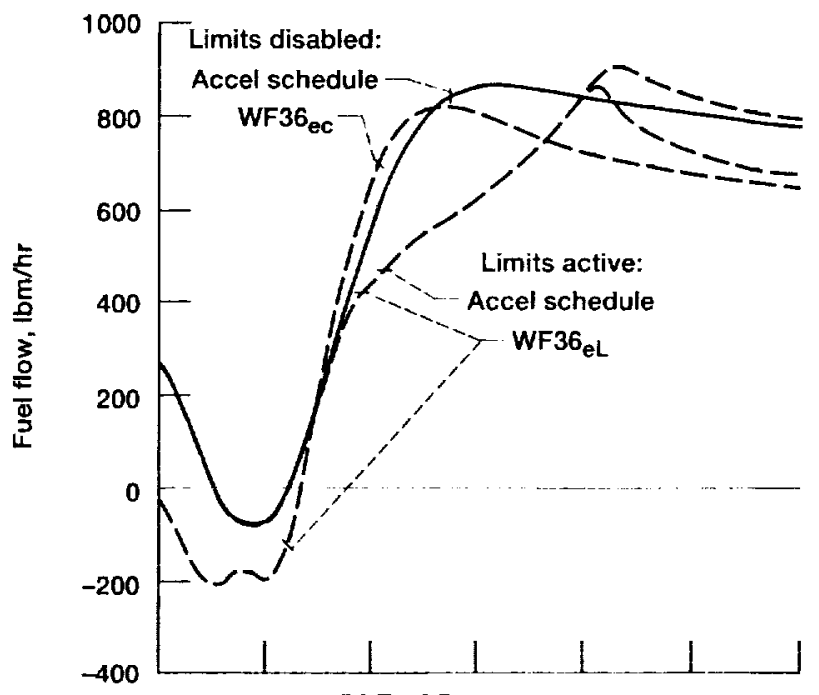

(b) Fuel flow response.

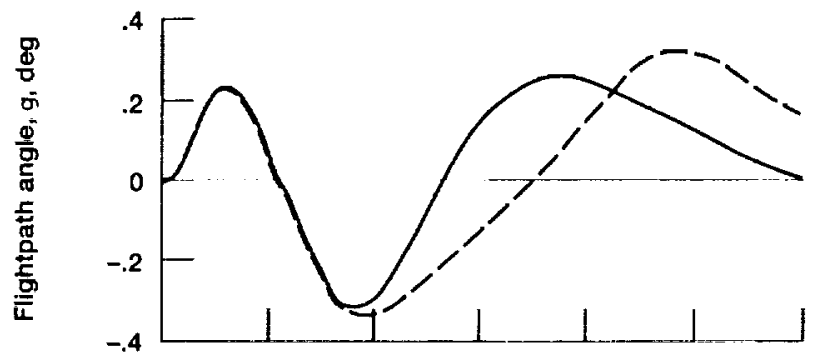

(c) Flightpath angle response.

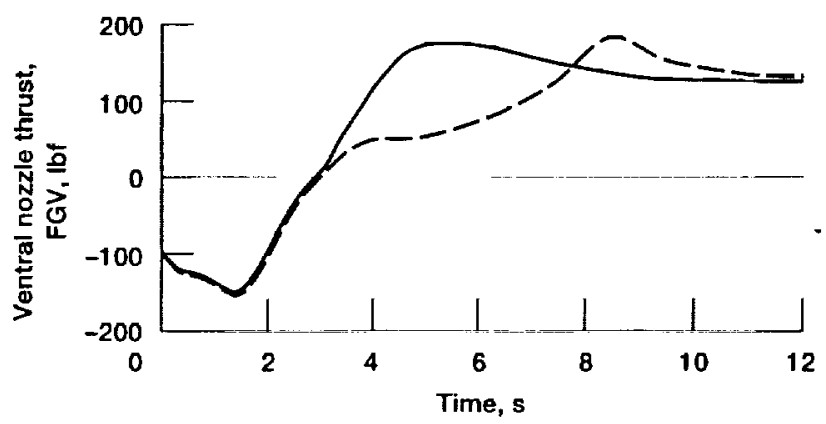

(d) Ventral nozzle thrust response.

Figure 12.-Comparison of response to deceleration command for systems with and without active limit protection. 


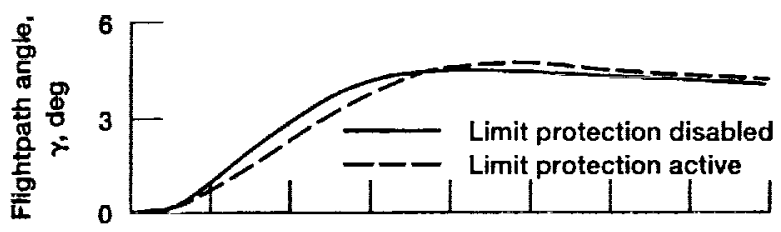

(a) Flight path angle response.

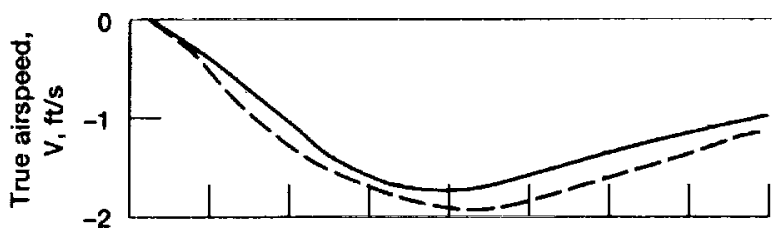

(b) True airspeed response.

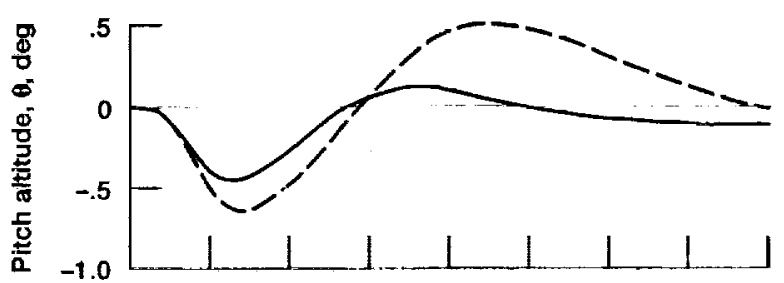

(c) Pitch altitude response.

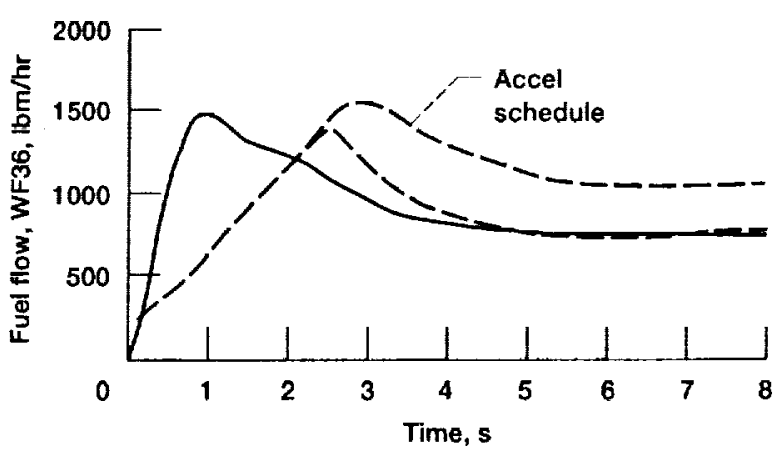

(d) Fuel flow response.

Figure 13.-Comparison of responses to $\gamma_{C}=4^{\circ}$ step command for systems with and without active limit protection.

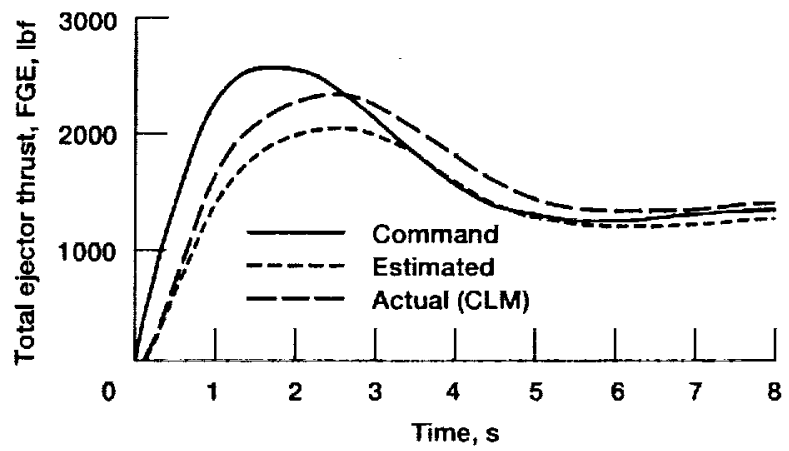

Figure 14.-Comparison of commanded, estimated, and component-level model thrust responses to $g_{c}=4^{n}$ step command. 
Public reporting burden for this collection of information is estimated to average 1 hour per response. including the time for reviewing instructions, searching existing data sources, gathering and maintaining the data needed, and completing and reviewing the collection of information. Send comments regarding this burden estimate or any other aspect of this collection of information including suggestions for reducing this burden, to Washington Headquarters Services, Difectorate for information Operations and Reports, 1215 Jefferson Davis Highway, Suite 1204. Arlington, VA 22202-4302, and to the Office of Management and Budget, Paperwork Peduction Project (0704-0188). Washington, DC 20503

\begin{tabular}{|l|c|c|}
\hline 1. AGENCY USE ONLY (Leave blank) & $\begin{array}{c}\text { 2. REPORT DATE } \\
\text { October } 1992\end{array}$ & $\begin{array}{r}\text { 3. REPORT TYPE AND DATES COVERED } \\
\text { Technical Memorandum }\end{array}$ \\
\hline
\end{tabular}

\section{TITLE AND SUBTITLE}

5. FUNDING NUMBERS

Propulsion System Performance Resulting From an Integrated

Flight/Propulsion Control Design

6. AUTHOR(S)

Duane Mattern and Sanjay Garg

WU $-505-62-50$

\section{PERFORMING ORGANIZATION NAME(S) AND ADDRESS(ES)}

National Aeronautics and Space Administration

Lewis Research Center

Cleveland, Ohio 44135-3191

8. PeRforming organization REPORT NUMBER

E-7339

9. SPONSORING/MONITORING AGENCY NAMES(S) AND ADDRESS(ES)

10. SPONSORING/MONITORING AGENCY REPORT NUMBER

National Aeronautics and Space Administration

Washington, D.C. 20546-0001

NASA TM- 105874

11. SUPPLEMENTARY NOTES

Prepared for the AIAA Guidance, Navigation, and Control Conference sponsored by the American Institute of Aeronautics and Astronautics, Ulilon Ilead, South Carolina, August 10 - 12, 1992. Duane Mattern, Sverdrup Technology, Inc., Lewis Rescarch Center Group, 200I Acrospace Parkway, Brook Park, Ohio 44142; and Sanjay Garg, Lewis Research Center, Cleveland, Ohio. Responsible person, Sanjay Garg, (216) 433-8186.

12a. DISTRIBUTION/AVAILABILITY STATEMENT

12b. DISTRIBUTION CODE

Unclassified - Unlimited

Subject Categories 7 and 8

13. ABSTRACT (Maximum 200 words)

Propulsion-system-specific results are presented from the application of the integrated methodology for propulsion and airframe control (IMPAC) design approach to integrated flight/propulsion control design for a short-takeoff-andvertical-landing (STOVL) aircraft in transition flight. The IMPAC method is briefly discussed and the propulsion system specifications for the integrated control design are examined. The structure of a linear engine controller that results from partitioning a linear centralized controller is discussed. The details of a nonlincar propulsion control system are presented, including a scheme to protect the engine operational limits: the fan surge margin and the acceleration/deceleration schedule that limits the fucl flow. Also, a simple but effective multivariable integrator windup protection scheme is investigated. Nonlinear closed-loop simulation results are presented for two typical pilot commands for transition flight: acceleration while maintaining flightpath angle and a change in flightpath angle while maintaining airspeed. The simulation nonlinearities include the airframe/engine coupling, the actuator and sensor dynamics and limits, the protection scheme for the engine operational limits, and the integrator windup protection. Satisfactory performance of the total airframe plus engine system for transition flight, as defined by the specifications, was maintained during the limit operation of the closed-loop engine subsystem.

\section{SUBJECT TERMS}

Aircraft control; Propulsion; Propulsion control; Integration

16. PRICE CODE

A03

\begin{tabular}{c|c|c|}
\hline 17. SECURITY CLASSIFICATION \\
$\begin{array}{c}\text { OF REPORT } \\
\text { Unclassified }\end{array}$ & $\begin{array}{c}\text { 18. SECURITY CLASSIFICATION } \\
\text { OF THIS PAGE } \\
\text { Unclassified }\end{array}$ & $\begin{array}{c}\text { 19. SECURITY CLASSIFICATION } \\
\text { OF ABSTRACT } \\
\text { Unclassified }\end{array}$
\end{tabular}


